\title{
FRANCAVILLA, ROBERTO. CALLIGRAFIE MORALII. DISCORSI DEL POTERE IN JOSÉ CARDOSO PIRES, ANTÓNIO LOBO ANTUNES, HERBERTO HELDER. PISA: ETS, 2018.
}

\author{
ADA MILANI"
}

${ }^{*}$ Professora da Università degli Studi di Genova, Itália. 
Calligrafie morali. Discorsi del potere in José Cardoso Pires, António Lobo Antunes, Herberto Helder - livro que acaba de ser editado pela editora italiana ETS na coleção "Oficina Lusitana" - é uma recolha de ensaios sobre três textos fundamentais da literatura portuguesa: O Delfim (1968) de José Cardoso Pires, Os cus de Judas (1979) de António Lobo Antunes e Teorema (1963) de Herberto Helder. A análise de Roberto Francavilla - professor de literatura portuguesa e brasileira na Universidade de Gênova (e precedentemente na Universidade de Siena), além de tradutor - leva a interpretar as obras em questão, publicadas em períodos e circunstâncias diferentes embora relativamente semelhantes, como uma complexa textura onde é possível enlaçar os fios centrais para um enquadramento da literatura portuguesa do século XX. Ao longo dos três capítulos que compõem o volume - "I personaggi de II Delfino di José Cardoso Pires", "Cuori di tenebra e di filo spinato (su In culo al mondo di António Lobo Antunes)", "L'inferno è più eterno del cielo (su Teorema di Herberto Helder e la riscrittura del mito inesiano)" - afloram, de fato, algumas temáticas fundamentais da literatura portuguesa contemporânea: o sebastianismo messiânico; a representação da história e dos seus traumas; a consolidação, a resistência e a reação à ideologia colonial; a relação entre escrita e poder; a dialética da alteridade entre a paisagem rural e o espaço ultramarino, entre a subjetividade hegemônica e a figura do africano, entre o cosmopolitismo e o provincianismo. Para além destes, outro tópico destaca-se no perfil geral, merecendo um discurso específico, nomeadamente, a saudade como cifra estética, código retórico e categoria filosófica do espírito que - sempre refratária às tentativas de definição - "[...] pervade della sua aura malinconica almeno quattro secoli di letteratura nelle sue più intricate connessioni con la Storia, la spiritualità, la politica e il contesto sociale" ${ }^{1}$ (FRANCAVILLA, 2018, p. 9).

Para melhor desenvolver as referidas linhas temáticas, Francavilla explora, paralelamente, três personagens originadas no mito e na tradição. Em primeiro lugar, o marialva de José Cardoso Pires, uma precisa tipologia social e popular enquanto protótipo humano da hegemonia machista e fascistoide, paradigma da sociedade lusitana que afunda as raízes na história portuguesa dos últimos três séculos e participa, com seus mitos e suas verdades, à manutenção do status

1 "[...] infunde da sua aura melancólica pelo menos quatro séculos de literatura nas suas conexões com a História, a espiritualidade, a política e o contexto social”. Tradução minha. 
quo daquela frágil sociedade moribunda. Objeto de atenção do segundo grupo de ensaios é a figura do veterano de António Lobo Antunes, que, depois da experiência traumática da Guerra Colonial, não tem possibilidade de se redimir nem de alcançar os contornos da própria identidade e da própria pertença à nação. Relativamente à análise da obra de Herberto Helder, surge, enfim, a imagem de um inteiro povo, que, obrigado a prestar uma macabra homenagem à rainha cadáver, contribui a construir um mito nacional impregnado dos sentimentos de morte e renascença:

Il popolo inconsapevole eppure vero destinatario del mito aderisce al luogo canonico della partecipazione collettiva, privata di elementi di riflessione e pertanto apolitica e, di conseguenza, facilmente conducibile a esperienze e risposte di natura isterica.[...] II popolo, che è il pubblico, inconsapevole destinatario dei segni che ne plasmano e ne codificano l'identità e l'inconscio collettivo, si erge a garante collegiale dell'esemplarità del castigo e insieme avido spettatore della festa pubblica organizzata per il suo osceno divertimento. Il popolo si unisce in una fratellanza orgiastica creando, inconsapevolmente, un monumento incorruttibile di identità collettiva [...].2 (ibid., p. 131-132)

Vinculados ao perdido esplendor de Portugal, os motivos e as figuras fulcrais dos três textos examinados entrecruzam-se, por sua vez, com um discurso de caráter intimamente político onde emergem, em forma dialética, questões como a postura do escritor e a natureza do texto em relação ao poder:

Se è vero che la letteratura, che si costruisce sull'invenzione, sull'immaginario e sul patto di verosimiglianza, di mimesi fra realtà e finzione, non ha come principale aspirazione il disvelamento della verità e dei suoi contorni, è vero anche che ci sono opere e ci sono scrittori che si rivelano funzionali - e talvolta indispensabili - alla sua

2 "O povo inconsciente e, ainda assim, verdadeiro destinatário do mito adere ao lugar canônico da participação coletiva, privada de elementos de reflexão, portanto, apolítica, e consequentemente reconduzível, sem esforço, a experiências e repostas de natureza histérica. [...] O povo, que é o público, inconsciente destinatário dos signos que plasmam e codificam a sua identidade e o inconsciente coletivo, ergue-se a garante colegial da exemplaridade do castigo e ao mesmo tempo é ávido espectador da festa pública organizada para o seu obsceno deleite. O povo une-se numa irmandade orgiástica criando, inconscientemente, um monumento incorruptível de identidade coletiva." Tradução minha. 
decifrazione, fornendo strumenti fondamentali per le sue possibili interpretazioni. ${ }^{3}$ (ibid., p. 16)

Calligrafie morali, título que Roberto Francavilla, significativa e felizmente, escolheu para a sua recolha, retoma uma declaração de José Cardoso Pires, o qual, em 1977, lembrando uma conversa tida com o escritor italiano Elio Vittorini, afirmou que "cada escritor possui a própria caligrafia moral". Na opinião de Francavilla, a escrita de Cardoso Pires testemunha que, entre as funções do intelectual, reside o dever de indagar a complexidade da natureza humana, do contexto histórico-social e de sanear os lugares da memória obstruídos pelas estratégias do esquecimento, obstinadamente levadas a cabo pelo discurso do poder. Escreve Francavilla: "La letteratura serve a ritagliare il profilo dei fatti dal velo del consenso generalizzato, a esplicarne le archeologie, le pratiche discorsive insite in ogni microfisica del potere"4 (ibid., p. 16). Nesse sentido, a escrita literária estaria orientada pela ética da verdade enquanto princípio fundamental da democracia, correspondendo ao conceito filosófico de parrésia, que, herdado pela tradição clássica, sugere a prática de exprimir com franqueza - perseguindo um dever de natureza moral - o que se considera verdadeiro. José Cardoso Pires assume, sem dúvida, a obrigação de lutar contra a desmemória - "un lento, pericolosissimo e apparentemente inarrestabile processo di opacizzazione pianificata della memoria collettiva" - ${ }^{5}$ (ibid., p. 17), por esse motivo, $O$ Delfim é um romance indispensável para a compreensão das relações entre memória, verdade e poder no Portugal salazarista. A leitura do romance deve ser entendida, segundo Roberto Francavilla, como uma tentativa de decifrar o complexo da sociedade sob o Estado Novo, através dos seus símbolos, dos seus mitos, dos seus sonhos e pesadelos: o resultado é uma improvisa aporia onde o mito se quebra, a circularidade do tempo se bloqueia, as hierarquias do poder

3 "Se é verdade que a literatura, que está construída na invenção, no imaginário e no pacto de verissimilhança, de mimese entre realidade e ficção, não tem como principal aspiração o desvelamento da verdade e dos seus contornos, é também certo que existem obras e escritores que se revelam funcionais - e às vezes indispensáveis - à sua decifração, fornecendo instrumentos fundamentais para suas possíveis interpretações." Tradução minha.

4 "A literatura serve para recortar o perfil dos fatos do véu de consenso generalizado, a explicar as arqueologias, as práticas discursivas inerentes a toda metafísica do poder ."(Ibi, p. 16).

5 "Um lento, muito perigoso e aparentemente incessante processo de opacificação planificada da memória coletiva." Tradução minha. 
se desestabilizam. Nesse processo de fragmentação dos mitos, Os cus de Judas representa, de maneira semelhante, outro exemplo paradigmático para decifrar o trauma e a inversão do olhar dos portugueses sobre si mesmos e sobre o UItramar: na transição pós-25 de Abril, a literatura portuguesa teve a necessidade de construir "un apparato di anticorpi che impedissero il subdolo trascinamento nella contemporaneità delle più fuorvianti pratiche della desmemória"6 (ibid., p. 79). O romance de Lobo Antunes - assumindo-se como anamnese - cria, manipula e desconstrói o mito cultural da nação como comunidade imaginada a partir de um específico espaço significante, ou seja a África:

L'apporto di romanzi come Os cus de Judas risulta fondamentale nel quadro della decostruzione dei miti coloniali elaborati dalla propaganda [...]: nel periodo in cui vengono pubblicati, le scomode verità della Storia sono state sistematicamente zittite, rimosse o, più raramente, rivestite di una patina scontata di retorica, in parte nel tentativo di assecondare un'afasia istituzionale decretata alla stregua di un patto silenzioso nel nome di una sorta di riconciliazione nazionale, in parte rispondendo ad un plausibile (e forse condivisibile) desiderio di rivolgere lo sguardo al futuro, scrollandosi di dosso pesi così soverchianti e tentando di guarire cicatrici così profonde.? (ibid., p. 73)

Por fim, Teorema de Herberto Helder, texto que ocupa uma posição limiar entre o conto e a prosa poética, não se limitando a questionar o respeito das constantes do mito, abala os modelos canônicos de leitura, agindo justamente no efeito de estranhamento, na alteração dos códigos temporais e na entropia das informações. Mais uma vez, o discurso do poder, o mito imperialista e a missão lusitana ultramarina encontram-se constantemente rescritos: "[...] la Storia come processo diacronico si inceppa, si interrompe e, come riavvolgendosi su se

6 "Um sistema de anticorpos que impedissem o subtil arrastamento na contemporaneidade das mais enganosas práticas da desmemória." Tradução minha.

7 "A contribuição de romances como Os cus de Judas revela-se fundamental no quadro da desconstrução dos mitos coloniais elaborados pela propaganda [...]; no ato da publicação, as incômodas verdades da história foram sistematicamente silenciadas, removidas ou, mais raramente, revestidas por uma pátina óbvia de retórica, em parte procurando apoiar uma afasia institucional decretada à maneira de um pacto silencioso em nome da reconciliação nacional, em parte respondendo a um plausível (e talvez aceitável) desejo de olhar para o futuro, livrando-se de fardos tão graves e tentando curar cicatrizes tão profundas." Tradução minha. 
stessa, anticipa secondo libere ellissi [...] i fatti evenemenziali di cui si compone il suo cammino"s (ibid., p. 125).

Partindo do pressuposto que, nas complexas relações entre literatura e poder, o mito pode constituir um elemento funcional na implantação do consenso, na estruturação da propaganda e nas estratégias de identificação (étnica, política e religiosa) - enquanto, pelo contrário, a literatura destrói os falsos mitos insinuando elementos de mudança -, Roberto Francavilla analisa detalhadamente a construção e a desconstrução dos mitos nas três obras-primas de José Cardoso Pires, António Lobo Antunes e Herberto Helder. Apoiando-se numa escrita refinada, de grande profundidade crítica, rica em referências a nível literário, sociológico, filosófico, cinematográfico e artístico, o autor confirma-se, portanto, como uma das vozes mais influentes no panorama italiano dos Estudos Lusofónos e projeta o leitor no complexo quadro histórico-social e na complexa rede de mitologias político-coloniais que contribuíram a traçar a isotopia nacional e que são, portanto, imprescindíveis para a compreensão dos rumos de boa parte da literatura portuguesa do século XX.

\section{Referência}

FRANCAVILLA, Roberto. Calligrafie morali. Discorsi del potere in José Cardoso Pires, António Lobo Antunes, Herberto Helder. Pisa: ETS, 2018. (Col. Oficina Lusitana).

8 "[...] a História como processo diacrônico bloqueia-se, interrompe-se e, quase enrolando-se sobre si mesma, antecipa segundo livres elipses [...] os fatos evenemenciais de que o seu caminho se compõe." Tradução minha. 